\title{
Managerial Roles of Presidents in Ontario, Canada Colleges
}

\author{
Blair A. McMurchy \\ University of Reading, $U K$
}

\begin{abstract}
This study examines the role of the President at the tertiary level within the province of Ontario, Canada in an effort to reveal and substantiate the challenges faced by them in the twenty-first century. This study aims to identify the extent to which the new public management ideologies, that impacted over the past decade the area of higher education, influenced their managerial roles. Determining how college Presidents understand their role, particularly how they act in that role, is extremely important since there is evidence that they contribute significantly to the achievement of strategic goals of the colleges. Moreover, the findings of this study will help the Board of Governors in making hiring decisions in the future, as well as determine if particular training is required for the candidates chosen for such position.

Central to this study was Role Theory. The research model used was based on Mintzberg's taxonomy of managerial roles. According to the results of this study, it can be concluded that the job of postsecondary college presidents has changed in the past two decades or so, to become more managerial in nature.
\end{abstract}

\section{Introduction}

The Ontario higher education system is the largest in Canada, consisting of 18 universities and 24 colleges of applied arts and technology. These figures do not take into consideration the private sector which consists of 500 career colleges, according to the Ontario Ministry of Colleges and Universities [15]. While universities are offering programs leading to undergraduate and graduate degrees, the Ontario's Colleges of Applied Arts and Technology (CAATs) are providing a wide range of post-secondary education and training programs which complement universities' educational offerings, contributing significantly to the economic and social development of the province. Private career colleges add to the above abundance of instructional possibilities a wide range of training opportunities, focusing mostly on programs such as business and computer technology programming, aesthetics and hairstyling, trucking and welding programs.
According to the Canadian Constitution, higher education is treated as a matter of local (provincial or territorial) interest [7]. As a result, an exclusive jurisdiction has been granted to provincial governments to develop, control and monitor the higher education legislation, policy development and regulation. Notwithstanding this, the federal government still plays an important role by being actively involved in the areas of provincial funding transfers, student financial assistance, support for research, tax measures and support for individuals' saving for an education.

This study delves into the different tasks and roles that college presidents are committed to, disclosing valuable information about who they are, and how they are acting in order to be successful in their positions. College presidents are expected to ensure that the post-secondary institution they lead can appropriately meet the institutional stakeholders' expectations.

Describing the presidents' working habitat will help with understanding the managerial roles they emphasize the most, as well as the value of change, if any, in their roles over the past two decades. As a result, a brief description of the college system in Ontario is inherently necessary.

CAATs were created in the mid-sixties in order to respond to a number of societal and envisioned economic needs. Increased demographics, demands for universal access to education, economic growth and expansion were some of the factors that led the provincial government of Ontario to create them on May 21, 1965 through a Statement in the Legislature that was presented by then Minister of Education, Honorable Bill Davis.

According to Dennison [9], community colleges' main characteristics revolved around the following aspects: unrestricted access; community orientation; comprehensiveness; responsiveness to societal needs; and emphasis on teaching and training. The major responsibilities of the CAATs were, according to the Statement in the Legislature, to provide courses that, in their type and level, were not suited to the secondary school setting, to meet the educational needs of the adults and out-of-school youth, irrespective of the fact whether or not they were secondary school graduates, as well as meet the educational needs of graduates from any secondary 
school program apart from those who wish to attend university.

Over the past five decades a lot of changes occurred in this sector of higher education. External environment factors - demographic trends, government policies on post-secondary education at both provincial and federal levels, scarcity of resources - and internal environment factors - labor relations (strikes in 1979, 1986 and 1989), and quest for excellence - have shaped the way in which community colleges tailored their strategic options.

Over the years, new models of governance have been developed, and different types of hierarchical structures gradually accompanied this parade of management retrenchment initiatives. There have been many reviews [33], [23], [11], [22], [31], [24] in the field of higher education in Ontario aiming at promoting changes on the existing governance arrangements. These reviews addressed issues related to the reconciling quality and accessibility within funding constraints, the relationships between teaching and research, community colleges and universities, public and private sectors. As a result, the government reacted by passing legislation so that colleges could meet their quantitative (student enrolment numbers) and qualitative (quality of instruction) expectations. The provincial government provided, also, over the years, for increasingly diverse roles that colleges needed to play, and allowed colleges to partner with private businesses, industry and universities to engage in entrepreneurial opportunities.

In spite of all the changes and challenges that have emerged over the years to all the stakeholders of this particular sector of higher education, today the benefits brought by the colleges to their communities are enormous.

According to Robinson and Christophersen [25] the benefits can be tracked as regional economic benefits, higher earnings captured by existing students, broad collection of social benefits (improved health, reduced crime, lower welfare, and unemployment), and return on invest to taxpayers for their support of Ontario's 24 community colleges.

\section{Literature Review}

This study relies on existing literature and aims at revealing some pertinent information about the college presidents' responsibilities, challenges, and leadership styles as system and environmental changes impacted on their academic and administrative activities.

The existing literature on postsecondary college presidents, in general, and, on Ontario postsecondary college presidents, in particular, is limited. In North America, particularly in Canada, there are only two notable recent studies, however, they did not focus on postsecondary colleges governance platform: one which was conducted by Jones et al. [2] who examined the roles and responsibilities of the associate deans in Canadian universities and the other by David [8] who examined the roles of the academic deans in Canadian universities. Both studies tried to ascertain whether these roles have in fact changed as a result of the new managerial paradigm that has penetrated both the higher education systems and institutions worldwide. The studies confirmed the expectations in the sense that both of them consistently revealed that the Canadian postsecondary education system has been affected marginally by the new public management ideologies.

Leadership, management and administration require different, but overlapping skills, knowledge and abilities. However, at an operative level they are poorly differentiated. Role confusion and overlapping between these roles may give rise to conflict of interest, inequalities in workload and inappropriately applied expertise. Inevitably, according to Law et al. [16], this contributes to inefficiencies, diminished job satisfaction and reduced quality of overall management.

Given these circumstances, Segall et al. [27] posited that, in the last decade or so, all education leaders seem to understand the importance of more market-oriented, student-centred, business-like management and accountability strategies while preserving their academic mission, focus and values. In order to understand the nature of the managerial roles adopted and emphasized by postsecondary college presidents it is important to understand the context in which they conduct their daily activities, namely higher education.

The specificity of the context can be attributed to a number of factors. These factors are: duality of organizational structure - the simultaneous existence of an administrative and academic hierarchy [19]; the existence of professionalism and specialization existence of dual allegiance i.e. first to the discipline and second to the institution [10]; existence of blurred levels of organizational responsibility and control - having knowledge intensive production processes that require decentralization and fragmentation of decision-making power [4]; and the existence of goal ambiguity - post-secondary institutions try to be all things to all people [10].

Moreover, according to Gourley [12] there has been a seismic shift in higher education embracing the unprecedented opportunities offered by the global technology-fuelled society. In this respect, one of the major transforming factors, enabled by advances in communications and information technology, is that of globalization through the mobility of ideas, capital and people. In this new context, new roles for the higher education providers emerged, such as fundraising and industry liaison 
representative to name a couple. In addition, there are new world players - India and China that have emerged as education provider powerhouses [13].

Central to this study is Role Theory. According to the Role Theory, human behavior is guided by expectations held both by the individual and by the other people in his/her proximity. The expectations correspond to different roles individuals perform or enact in their daily lives. Most people hold preconceived notions of the expectations of the different roles. Individuals generally have and manage many roles which consist of a set of rules or norms that function as plans or blueprints to guide their behavior. Roles specify what goals should be pursued, what tasks must be accomplished, and what performances are required in a given scenario or situation. [20]

Role theory holds that a substantial portion of observable, day-to-day social behavior is similar to the activities that are carrying out by individuals in their roles, the same way as actors carry out their roles on the stage or ballplayers theirs on the playfield. In other words, an individual is literally seen or perceived as an 'actor', or 'performer' who has to keep to a script where improvisation is limited if not impossible and not permitted. Such roles may be seen as part of a social system, whose elements are assigned certain functions in the maintenance of the whole.

From this holistic perspective, the functionality of roles becomes the key to understanding patterns of behavior [14] and it is this that is the platform of this proposed study. The rationale of this stems from the facts that since roles create regular patterns of behavior and thus a measure of predictability, allowing individuals to function effectively because they know what to expect of others, makes it possible for the researcher to make generalizations about the upper level management.

The concept of role is related to but must be distinguished though from the concept of social position. While a position is an element of organizational autonomy, a location in a social space and a category of organization membership, a role is an aspect of organizational physiology that involves function, adaptation and processes.[18]

In his study, Bragg [3] answered the "good president" challenges by proposing six core knowledge areas that are, in his opinion, sine qua non conditions to success. They included the following: (1) knowledge of the mission, philosophy, and history of the institution, (2) learner-centered orientation, (3) instructional leadership, (4) information and educational technologies, (5) assessment and accountability, and (6) administrative preparation. All of these knowledge areas are not expected to remain constant over time, but continue to evolve. Bragg [3], also, stated that presidents are expected to "possess democratic leadership, creative management, and finely tuned human relation skills" (20). It is evident that presidents need to be multiskilled, as well as, possess a plethora of knowledge in many areas. To further the present analysis, some interest has been spent on determining the present responsibilities of community college presidents.

The college presidents are mainly responsible for: a) developing and implementing progressive and community responsive college philosophies, including comprehensive strategic plans; b) developing, maintaining and evaluating the academic programs and student services of the college while creating climates inductive of student learning enhancement; c) developing and maintaining appropriate administrative organization in order to insure effective and efficient management of the college and its resources; d) developing and maintaining personnel operation which includes the recruitment, selection, development, compensation and evaluation of all college staff; e) prepare, recommend and administer the annual operating and capital budgets as approved by the Board, e) internal and external communications with the college stakeholders, being the college's chief spokesperson and representing the college to the general public.

In terms of personal skills, the leadership aspect is a critical component, especially for those involved in managing academic affairs. According to Bragg [5]:

[the president as a leader] creates the stage for future operations while managing dayto-day activities. [Furthermore] the role of the President is not one that is easily definable. Presidents of today have a much wider range of responsibilities than in the past. The focus of their position has tended to shift away from the student and move more towards administrative obligations with a focus on the faculty. The skills needed to effectively perform the various duties assigned to a college President are not exhaustive and continue to change as the academic environment evolves (19).

"The role of the president is shaped by his own personality and by the expectations of the group or groups in which his role is performed" [25] (254). The president "performs a multitude of roles and within each of these, depending upon the social context, he will behave in a particular individualistic style" [25] (255) that mostly depends on his personality.

The application of role theory in the analysis of organizations is of significance to this study. In this respect, it can be argued that for the purpose of this study, role theory offers a good middle ground between rigid structuralism and constructivism /postmodernism ideologies. If one can imagine an organization that is small enough to be amenable for an empirical study and whose structure is complex enough to provide a wide variety of social positions 
and role-standardizing forces it can be observed that any individual is seen as a cog in the apparatus, what he/she thinks and does is actually determined by the requirements in the organization structure. [16]

In the future presidents must be prepared to deal with these situations as well as the changes that will continue to occur across campuses both within the institutional structure, as well as with the faculty, staff, and students. Semantically, there is a clear demarcation line among the roles, responsibilities and duties concepts. Cohen and Brawer [6] stated that the conceptualization of a role:

...is based on the assumptions that (1) interpersonal/environmental contexts determine role - that is other people's anticipations of how a person playing a certain role will act are, in fact, the determinants of "proper" role behavior; (2) each individual plays a number of roles; (3) the role expectations held by individuals or defined by other members of a group are related to the individual's position in a given social system; (4) the individual's position in the social system affects the nature of his social relationship as well as his role expectations; and (5) role expectations emanate both from the broader society - that is, from the individual's reference group - and from his own perception of the situation (72).

Human personality has been virtually excluded from traditional organization theory. This is clearly manifested in Weber's [32] theory of bureaucracy in which he portrays the bureaucratic organization as a monolithic edifice where norms are clearly defined and consistently applied. The agencies of role socialization succeed in inducing acceptance of organizational requirements, and the sanctions of the system provide constraints and incentives needed to maintain behavioral conformity. Every individual is given a clearly defined role and readily fills it in. There is little room for more complex choice, individual creativity or social change. [32]

For Weber, bureaucracy as an ideal type is administered by "experts" in a spirit of impersonal rationality and is operated on a principle of discipline according to which each member performs his required duties or roles as efficiently as possible. Rationality in decision-making and obedience in performance are the pivots on which the entire system operates. Emotion, in this case, is regarded as a hindrance to efficiency and has to be excluded from the bureaucratic process. [32]

Weber noted the existence of three types of authority: traditional, charismatic and rational-legal. The rational-legal administrator is the pillar of bureaucracy as he/she receives his/her legitimacy impersonally from the system by virtue of his/her technical competence. In Weber's ideal, there is no place for affection. It is only the charismatic leader who becomes emotionally important to his/her followers and who must personally validate his/her right to lead [32].

Based on the role theory, postsecondary college presidents are actors in a managerial role that has to meet the expectations of all stakeholders. Defining managerial roles is rooted in Barnard's theory of cooperative behaviour and interest in executive behaviours [1]. Three distinct schools of thought have emerged as a result of Barnard's contribution: the institutional school represented by Selznick [28], the decision-making school represented by Herbert Simon [29] and the human relations school represented by Mayo [18]. Even though Carlson [5] is credited with the first classical work about executives' behaviour, the first modern study of executive behaviour is attributed to Mintzberg [21].

According to Mintzberg [21], the manager's job, in our case that of postsecondary college president, can be specifically described within three different categories - informational, interpersonal and decisional roles. These roles are continuously changing as the environment in which the presidents conducting their daily routine activities changes. The following is a prescribed list of such possible generic roles.

In terms of informational roles category, the president is expected to act as a monitor, disseminator and spokesman. As a monitor, the president is constantly scrutinizing the external environment for more information and data with respect to the latest developments. Internally, the president is constantly in contact with their subordinates looking to obtain both solicited and unsolicited information that is helpful in the managerial context. As a disseminator, the president is expected to circulate the gathered information, passing it on to the responsible parties within their control unit. As a spokesperson, the president is expected to release information to other parties outside of their control unit.

In the interpersonal roles category, the president is expected to act as a figurehead, a leader and a liaison. As a figurehead, the president is expected to perform various ceremonial duties which may include graduation ceremonies and academic appointments. As a leader, the president is supposed to assume responsibility for the work performed by the people under his/her command. Within this leadership role, the president needs to perform service, be accountable, fulfil a moral role, act as a steward, build diverse communities with trust and collaboration, and promote excellence. As a liaison, the president should build and maintain contact outside the vertical chain of command.

With respect to the decisional roles, the president is expected to act as an entrepreneur, disturbance handler, resource allocator, and negotiator. As 
entrepreneurs, the presidents would seek to improve their control unit from all perspectives - financial, teaching, and human resources - by providing a clear vision and articulate advice to their employees. As disturbance handlers, the presidents are expected to react promptly and offer solutions to problems resulting from situational pressures. As resource allocators, the presidents are supposed to properly decide how to fairly and equitably allocate all the resources among the members of their control unit. As negotiators, the presidents are expected to partake in negotiations both internally and externally.

\section{Research Question}

Based on the analysis of the existing literature research with respect to the managerial roles of the upper level management in tertiary education institutions, particularly, college presidents in the province of Ontario, Canada one issue seems to require some clarification. The present study tries to shed some light with respect to this matter when formulating the main research question which is: What are the most emphasized managerial roles that Ontario postsecondary college presidents are adopting in order to deal with present challenges posed by the new public management ideologies impacting the field of higher education?

\section{Methodology and Data Analysis}

In order to answer this question, as well as, to develop a rich and comprehensive understanding of the presidents' changing roles and responsibilities, a mix of quantitative and qualitative research approaches has been utilized. The quantitative part of the study aimed at gathering and analysing two distinct aspects about college presidents: the background factors and the most emphasized activities. Given the small sample size to draw from, as well as, the response rate, a qualitative analysis part has been added to the study. The qualitative part has been deemed as a good fit in this case since it will provide a broader view of presidents' managerial roles, responsibilities and actions since it complements the information obtained from the quantitative part of the study.

\subsection{Sample size}

In order to answer the research question it was important to understand the diversity of the different postsecondary institutions in Ontario since there is evidence that the roles of the presidents are impacted by a number of factors such as: the colleges' mandate, type of institution and language of communication and instruction. With respect to the college mandate, Ontario's postsecondary colleges are classified as: urban and regional. Given the fact that there are different catchment areas, in terms of geographic location and size, different student population makeup, it is reasonable to believe that the presidents' managerial roles and responsibilities may differ from one category to another.

In regards to the type of organization, in Ontario the taxonomy consisted of two different institutional entities: Colleges of Applied Arts and Technology (C.A.A.T.), and Institutes of Technology and Advanced Learning (I.T.A.L.). It will be extremely important to determine the extent to which the new (in the light of new Charter) institutional spin-offs have altered their reporting and/or hierarchical structure, as well as the administrative positions title. In terms of language of communication and instruction, in Ontario there are two types of colleges: English, or French speaking. It will be important to determine if in the French speaking institutions the role of the president is different than in the English speaking colleges, and if any, ascertain the reasons for that.

Summing up, the sample size, accounting for the factors listed above, consisted of twenty-four presidents across Ontario. The actual response rate was $37.5 \%$ which was considered sufficient to conduct the study.

\subsection{Data Collection}

For the quantitative part of the study, the data collection consisted of an online questionnaire. The data collection entailed the use of an "in person" semi structured interview. This paper includes only the results and the afferent data analysis of the quantitative part of the study since the qualitative part of the study has not been completed, yet.

The methodology of collecting data online is no longer new and according to Schmidt [26] one of the major benefits of such approach is the access to a largely dispersed population of potential participants besides the pecuniary aspects and efficiency and effectiveness associated with the collection of data.

The online questionnaire entitled a "Participant Questionnaire" consisted of two parts. The first part - Part A - addressed issues related to the presidents' academic and professional background. The second part - Part B - was developed around Mintzberg's taxonomy of managerial roles and addressed issues related to the presidents' most emphasized activities while conducting their work. Each of the ten managerial roles (latent variables) was measured by three distinct statements (indicator variables). All participants were asked to indicate the extent to which each managerial role was used in their daily routine using a four-point Likert-like type scale: 1. Not At All; 2. A Little; 3. Some; and 4. A Lot. As a research measurement instrument the questionnaire was tested for validity (content and context) and 
reliability. While both validity aspects were met since the instrument was previously tested by Mech [19] and reviewed by Mintzberg, the reliability analysis revealed a good Cronbach's Alpha (.831) since its value was between 0.8 and 0.9 .

The "in person" interviews were encapsulated under the title "Open End Interview Questions" and consisted of a semi-structured interviews containing a set of open - end questions aimed at exploring issues pertaining to presidents' personal views, norms, values, management style, working philosophy and future plans.

The interviews are expected to last between 30-45 minutes. The interviews will be carried out by the researcher and all the answers will be recorded on a voice recorder.

The choice for semi-structured over structured interviews was preferred in order to obtain rich, detailed answers. The interviewee insights about the changing roles of the presidents are expected to be relevant and important. The flexibility that is rendered by the semi-structured interviews helps with adjusting the emphases in the research as a result of significant issues that emerge in the free discussion. In other words, rather than expecting the interview to reflect and address the researcher's concerns and biases, it is of much greater interest to determine the interviewee's point of view and opinions about the proposed theme.

\section{Results}

The first part of the online questionnaire revealed important information about who the presidents are in terms of gender, age, previous position held, highest degree of education held, number of years of managerial experience and workplace characteristics. The data gathered from the study, namely the quantitative part, was subjected to statistical descriptive measures, particularly, rate of frequency and percentages.

\subsection{Background Factors}

The results revealed that: a.) the majority of the presidents $(66.67 \%)$ that participated in the study were males; b.) the age of the majority of the participants $(66.67 \%)$ was between $40-59$ years of age; c.) the majority of the participants $(66.67 \%)$ held a Vice-President position prior to their presidency term; d.) with small exceptions, majority of them have a doctoral degree $(44.45 \% \mathrm{PhD}$ and $33.33 \% \mathrm{EdD})$; e.) the majority of the presidents have over 11 years of managerial experience $(66.67 \%$ between 11-20 years of managerial experience while $22.22 \%$ over 21 years); f.) with one exception, all the presidents worked in English speaking postsecondary institutions; g.) half of the participants worked in urban colleges $(55.55 \%)$ while the rest in regional ones; h.) with one exception, all participants worked in CAAT's.

\subsection{Managerial Roles}

The second part of the online questionnaire was aimed at determining the most emphasized activities routinely pursued by the presidents. After determining the frequencies, mean, range and mode for each of the activities it was concluded that the most emphasized activities were "encourage teamwork among your staff" and "represent the college to outside groups" while the least emphasized were "resolving problems that develop with other institutional units" and "put a stop to misbehaviour within or outside the College". Tallying up all the results, overall, it can be claimed that the most emphasized roles were the entrepreneur, spokesperson and figurehead, while the least emphasized roles were the negotiator and disturbance handler.

Analysing further the results from the second part of the questionnaire, it can be concluded that the president position is quite a complex one, demanding various and numerous activities to ensue in order to guarantee an efficient and effective running of a higher education institution. In this respect $25 \%$ of the presidents emphasize between 16-22 activities while another $25 \%$ of them between $8-15$ activities; the remaining $50 \%$ of the presidents emphasize only between 0-7 activities. That means that on a daily basis, the presidents are confronting numerous and different challenges that require them to perform various activities in order to ensure the successfulness of their job.

\section{Conclusions}

The findings of this study are very important for understanding who the college presidents are and what are the most emphasized managerial roles displayed as part of their executive behaviour. In spite of the fact that the sample size was limited some valid and valuable conclusions can be drawn. The conclusions drawn offer only a partial understanding of the college presidents managerial roles since they cover only the quantitative part of the study. More and detailed information is expected to be added once the qualitative part will be completed and analysed. Based on background factors analysis it can be concluded that the majority of college presidents are males, 40 -59 years of age who held a Vice-President position prior to the presidency term, who have obtained a doctoral degree and have between $11-20$ years of managerial experience in the field if higher education. 
Based on the analysis of the managerial roles analysis it can be concluded that overall, the findings of the study align with the existing literature on higher education in the sense that it confirms that the role of the postsecondary college presidents reflects the changes that impacted the field of higher education in the past two decades, in particular the new public management ideologies. According to the results of this study the job of postsecondary college presidents has become more managerial in nature in the light of the most activities and roles emphasized. In this respect it can be concluded that the role of the college president has, also, become more entrepreneurial, requiring a lot of skills and abilities that are needed to deal with daily challenging situations within their work setting.

Moreover, the study proves the fact that part of the postsecondary college presidents' success rests with their capacity to develop and maintain a large work-related network of relationships that eventually can be deemed helpful when the situations require. As educational leaders, postsecondary college presidents understand the importance of the marketoriented, student-centred, business-like management and accountability. Acting like figureheads when sharing the academic mission, institutional focus and values with external audiences or when looking for external support, whether pecuniary or not, postsecondary college presidents of today acknowledge that their job has become very complex and demanding in terms of skills, knowledge and abilities.

In stark contrast, college presidents tend not to act as disturbance handlers or negotiators since they consider these roles as not important or relevant to what they consider is expected of the position they occupy. To them, the activities associated with these roles are at the bottom of their managerial "ivory towers" concerns, as they feel more like embracing the mantra of college chief executive officers.

More information and a better contour of their managerial profile will be added to the existing one once the qualitative part of this study will be completed. A more nuanced and in-depth, sourcerich picture will be developed at the time and a better answer to the study research question will be formulated. Till then, based on the existing data and afferent results it can be claimed that the findings of the present study align with the existing literature research in the field of higher education.

\section{References}

[1] Barnard, C.I. (1938). The Functions of the Executive. Cambridge: Harvard University Press.

[2] Boyko, L. and Jones, G. (2008). The Roles and Responsibilities of Middle Management (Chairs and Deans) in Canadian Universities.
[3] Bragg, T. (2002). Improve Employee Commitment. Industrial Management, 7(8), $18-20$.

[4] Clark, B.C. (1983). The Contradictions of Change in Academic Systems. Higher Education, 12(1), 101-106.

[5] Carlson, S. (1951). Executive Behaviour: A Study of the Workload and the Working Methods of Managing Directors. Stockholm: Strombergs.

[6] Cohen, A. M. and Brawer, T.B. (1972). Confronting Identity: The Community College Institutions. Englewood Cliffs, Prentice Hall.

[7] Constitution Act (1982). s.93

[8] David, L. (2011) The Roles of the Academic Deans in Ontario Universities - Doctoral Thesis, OISE, Toronto.

[9] Dennison, J.D. (1996). Higher Education in British Columbia, 1945-1995: Opportunity and Diversity. Vancouver: University of British Columbia Press.

[10] File, J. (2000). A Comparative Perspective on Leadership and Institutional Change in, Cloete, N., Tembile, K. \& Phala, M., Leadership and Institutional Change in Higher Education. CHET: Pretoria.

[11] Gandz, J. (1988). The report of the Colleges Collective Bargaining Commission, Toronto.

[12] Gourley, W. (2007). Higher-ness or Further-ness, Classifying Higher Education in Further Education in England (HFE) at the Interface; Boundary Work, Boundary Objectives and Boundary Spanning, a working paper presented at the International Conference on Researching Transitions in Lifelong Learning, University of Sterling, June, 22-24.

[13] Group of Eight (2007). Seizing the Opportunities: A Policy Framework of Balanced Incentives in Higher Education and University Research.

[14] Hollis (1998). Press and Public Relations Manual, London: Hollis Directories.

[15] http://www.aucc.ca retrieved February 16, 2014.

[16] Law, S. and Glover, D. (2000). Educational Leadership and Learning: Practice, Policy and Research, Open University Press.

[17] Maassen, P., van Vught, F. (1994). Alternative Models of Governmental Steering in Higher Education. An Analysis of Steering Models and Policy-Instruments in Five Countries. In F. van Vught \& L. Goedegebuure (Eds) Comparative policy studies in Higher education. Utrecht: Lemma.

[18] Mayo, E. (1933) The Human Problem of an Industrial Civilization, Cambridge, MA: Harvard. 
[19] Mech, T. (1997). The Managerial Roles of Chief Academic Officers. Journal of Higher Education, 68(3), 282-298.

[20] Merton, R. (1934). On Sociological Theories of the Middle Range, pp. 39 - 53, from Merton Robert Social Theory and Social, New York: Simon and Schuster, The Free Press.

[21] Mintzberg, H. (1973). The Nature of Managerial Work. New York, N.Y.: Harper \& Row.

[22] Pascal, C. (1990) Overview. Orbit 29(1), 4 - 6.

[23] Pitman, W. (1986). The Report of the Advisor to the Minister of Colleges and Universities on the Governance of the Colleges of applied Arts and Technology. Toronto.

[24] Rae, B. (2005). Ontario: A leader in learning. Report and Recommendations, February.

[25] Robison, M. H., \& Christophersen, K. A. (2004). The socioeconomic benefits generated by 24 colleges of applied arts and technology in Ontario. Volume 1: Main report. Moscow.

[26] Schmidt, W. C. (1997). World-Wide Web Survey Research: Benefits, Potential Problems, and Solutions. Behavior Research Methods, Instruments and Computers, 29 (2), 274-279.

[27] Segall, E. A. (2007). Social Empathy: A New Paradigm to Address Poverty, Routledge.

[28] Selznick, P. (1957). Leadership in Administration; a Sociological Interpretation, Evanson, IL: Row, Peterson.

[29] Simon, H. (1947). A Study of Decision - Making Processes in Administration Organization, The Free Press.

[30] Skolnik, M.L. and W.F. McMullen (1970). An Analysis of Projections of the Demand for Engineers in Canada and Ontario and an Inquiry into Substitutions between Engineers and Technologists, Toronto : Committee of Presidents of Universities of Ontario.

[31] Smith, A.H. (1972). The Production of Scientific Knowledge in Ontario Universities. Toronto: Queen's Printer, 1972. p. 174. (Study prepared for the Commission on PostSecondary Education in Ontario).

[32] Weber, Max. The Theory of Social and Economic Organization. Translated by A.M. Henderson and Talcott Parsons. London: Collier Macmillan Publishers, 1947.

[33] Wright, D. (1972). Recent Developments in Higher Education in Ontario in W.R. Niblett and F.R. Butts, eds., World Yearbook of Education (London: Evans Bros. 1972) p. 297-309. 